\title{
Soft Computing System for the Diagnosis of Hormonal Imbalance
}

\author{
Ejodamen, Pius Uagbae ${ }^{1}$, and Ekong, Victor Eshiet ${ }^{2}$ \\ 1,2, Department of Computer Science, University of Uyo, Akwa Ibom State, Nigeria \\ pius247@gmail.com, victoreekong@uniuyo.edu.ng
}

\begin{abstract}
Soft computing, as a science of modelling systems, applies techniques such as evolutionary computing, fuzzy logic, and their hybrids to solve real life problems. Soft computing techniques are quite tolerant to incomplete, imprecise, and uncertainty when dealing with complex situations. This study adopts a hybrid of genetic algorithm and fuzzy logic in diagnosing hormonal imbalance. Hormones are chemical messengers that are vital for growth, reproduction, and are essential for human existence. Hormones may sometimes not be balanced which is a medical condition that often go unnoticed and it's quite difficult to be diagnosed by medical experts. Hormonal imbalance has several symptoms that could also be confused for other ailments. This proposed system serves as support for medical experts to improve the precision of diagnosis of hormonal imbalance. The study further demonstrates the effective hybridization of genetic algorithm and fuzzy logic in resolving human problems.
\end{abstract}

Keywords: Hormonal Imbalance, Soft Computing, Fuzzy Logic, Genetic Algorithm

\section{Introduction}

Hormones are chemical messengers which are produced in a human body organ and carried in the blood stream to other organs, where they may cause a change in a structure or functional activity [1]. Hormones send message signals to different cells in the body and are carried via the bloodstream. They are vital for growth, reproduction, maintaining constant body temperature, and performing the basic functions that are essential for life [2]. Bunzenmeyer in [3] cautions that hormones may appear normal but are imbalanced in relation to each other and their actions within the tissues. In [4] hormonal imbalance is described as a malfunction of hormones in the human body. Hormones such as estrogen, testosterone, adrenaline and insulin are extremely important chemical messengers that affect many aspects of our health. Known to be secreted by various glands and organs, including the thyroid, adrenals, pituitary, ovaries, testicles and pancreas, the entire endocrine system works together to control the level of these hormones circulating through the human body. If one or more is slightly imbalanced it can cause widespread, major health problems.

Hormonal imbalance is a leading cause of infertility [1-3]. Infertility means that couples having frequent intercourse for at least a year, so as to get pregnant, have been unsuccessful [5]. In [2] infertility is described as a complex disorder with significant medical, psychosocial, inequality, social injustice and economic problems. Noting that females are more fertile during the ages of 18 to 24 years, but fertility 
starts reducing after 27 years and deteriorates rapidly when she is above 35 years. It is however noteworthy that some medical conditions, such as Polycystic Ovaries Syndrome (PCOS), can cause infertility as well [6]. PCOS is mostly a hereditary problem and is associated with insulin resistance.

Beside infertility, hormonal imbalance can cause Pre-menstrual syndrome (PMS), irregular menses, fibrocystic breasts, as well as uterine fibroids [3]. It can also cause migraine especially in women who made use of drugs for estrogens replacement or for birth control [1].

Numerous lifestyle factors are also capable of causing hormonal imbalance such as poor diet, clothing, inadequate or lack of exercise, excessive intake of alcohol, tobacco, contraceptive medications, Hormone Replacement Therapy (HRT) [1-3, 7]. In [3], stress is found to also cause hormonal imbalance when more of the stress hormones including adrenalin and cortisol are produced. In other to meet up the demand for more of the stress hormones, progesterone, estrogen, testosterone and thyroid hormone production are reduced.

In women, some hormones produced include Follicle-Stimulating Hormone (FSH), Luteinizing Hormone (LH), prolactin, estrogens, oxytocin, progesterone, thyroid, Human Chorionic Gonadotropin and inhibin hormones among others [1-2]. The LH hormone is produced in the pituitary gland of women as well as in men. However, LH plays an important role in the menstrual cycle of women. The estrogen is the hormone that signals the pituitary gland to stop producing FSH and to commence the production of more $\mathrm{LH}$. This shift from FSH to LH causes the egg to be released from the ovary in a process called ovulation.

The probability of conception may be lower than expected for the woman's age if there is an increase in $\mathrm{FSH}$; which indicates a reduction in the production of good quality eggs and embryos for fertilization. On the other hand, levels of LH above normal in a woman could be an indication that the ovaries are absent or not functioning. While in young women, high levels could be an indication that puberty was early.

Prolactin plays the important role of stimulating the production of milk after childbirth; it triggers lactation in women. Estrogen and Progesterone are sex hormones mostly found in women [6, 8]. They are often regarded as sex hormones because they are more concentrated in the ovaries than other parts of the body such as the placenta of pregnant women [1]. Fluctuation in the levels of estrogen and progesterone hormones may negatively affect a woman's sexual desire, ovulation as well as her fertility [7]. When the progesterone is low in relation to the levels of estrogen present, it can lead to an irregular or shortened menstrual cycle.

Under normal circumstances, the highest chance of conception is attained via sexual intercourse on multiple occasions during the fertile period. The probability of conception is further lowered in women with hormonal imbalance [6].

\subsection{Symptoms of Hormonal Imbalance}

There are numerous symptoms that indicate the presence of Hormonal Imbalance. The following predominant symptoms have been suggested by experts [1-2, 6-9]; Headaches and Migraine, Changes in menstruation, Low sexual desire, Weight gain, Acne, Oily skin, Fever, Fatigue, Stress, Frequent hunger, Dizziness/Sleep Disorders, Excessive hair growth, Memory Fog, Mood Swings and Depression, Anxiety, Allergy, Endometriosis, Infertility, Urinary Tract Infections (UTIs) and Premenstrual syndrome (PMS). 
Ejodamen, Pius Uagbae, and Ekong, Victor Eshiet; Soft Computing System for the Diagnosis of Hormonal Imbalance. Transactions on Machine Learning and Artificial Intelligence, Volume 7 No 6 December (2019); pp: $30-42$

These symptoms of can range dramatically depending on the type of disorder or illness they cause. According to [7, 9] high estrogen levels contribute to disorders such as endometriosis or fibroids. Symptoms of diabetes often include weight gain, changes in appetite, nerve damage and problems with the eyesight. Some specific problems associated with some of the most common hormonal imbalances are [10-11]:

Estrogen dominance (changes in sleep patterns, changes in weight and appetite, higher perceived stress, slowed metabolism), Polycystic Ovarian Syndrome (PCOS) (infertility, weight gain, higher risk for diabetes, acne, abnormal hair growth), Low Estrogen (low sex drive, reproductive problems, menstrual irregularity, changes in mood), Hypothyroidism (slowed metabolism, weight gain, fatigue, anxiety, irritability, digestive issues and irregular periods), Low testosterone (erectile dysfunction, muscle loss, weight gain, fatigue and mood-related problems), Hyperthyroidism and Grave's disease (anxiety, thinning hair, weight loss, trouble sleeping and irregular heartbeats), Diabetes (weight gain, nerve damage (neuropathy), higher risk for vision loss, fatigue, trouble breathing, dry mouth and skin problems), Adrenal Fatigue (fatigue, muscle aches and pains, anxiety and depression, trouble sleeping, brain fog and reproductive problems).

Hormonal imbalances are multi-factorial disorders as they can be caused by a combination of factors such as diet, medical history, genetics, stress levels and exposure to toxins from the environment. The major contributors to hormonal imbalances according to [2] and [12] are; food allergies, overweight or obesity, high levels of inflammation caused by a poor diet and a sedentary lifestyle, genetic susceptibility, toxicity (exposures to pesticides, toxins, viruses, cigarettes, excessive alcohol and harmful chemicals), high amount of stress and a lack of enough sleep and rest.

\section{Related Work}

Genetic Algorithms (GA) are optimised search algorithms that model the natural evolution of humans [13]. It involves a random selection process to form the first-generation parents. Each pair of selected individuals undergo certain operations to produce a distinctly new generation. The operators in GA include crossover and mutation, which helps to produce a next generation that are genetically different but better than their parents. The general goal of GA is for successive generations to tend towards the optimum solution by searching until it meets the specified stop criteria [14].

GA, as a soft computing technique, has been widely used in improving medical service delivery. In [14] GA are utilized in a prototype system that used historical data to make intelligent clinical decisions in predicting heart diseases. The study randomly paired chromosomes so as to implement crossovers and mutation operators to ensure the generational diversity. A combination of GA and fuzzy logic is becoming common among researchers because it is faster, user-friendly, and easy to understand [13].

Zadeh in 1965 introduced Fuzzy sets as a means of representing and manipulating imprecise and fuzzy data [15]. Fuzzy Logic enables computers to relate with uncertainty [16]. Unlike standard set theory where an object belongs to a set or otherwise, a fuzzy logic theory provides a mathematical base to manipulate human reasoning which is often not precise. A fuzzy set comprises of elements with certain degrees of membership. A membership function determines the degree to which an element belong in a set. There are several membership functions including Triangular, Trapezoidal, Gaussian, S-function, and so on [1718]. 
Fuzzy Logic has been widely applied in the field of medicine. A comparative study in [19] demonstrates that Fuzzy Logic performed better than Analytical Hierarchical Process (AHP) in medical diagnosis. The study applied both methodologies with the aim of determining which diagnosis would match that of medical experts.

Fuzzy Logic has shown to combine well with other intelligent methodologies for medical diagnosis. In [17] a hybrid of Fuzzy Logic, ANN and Case Based Reasoning system is developed for the diagnosis of depression disorder. The study applied the triangular and trapezoidal membership functions for the input and output parameters. In developing a decision support system to predict the level of severity of Cardiovascular Diseases (CVD), [18] fuzzified the input to their system and fed it into a Neural Network (NN). The study also applied GA for optimizing the weight used in training the NN and the trained the NN was used for identifying the fuzzy rules for predicting the severity of CVD.

\section{Methodology}

A soft computing model is developed for the diagnosis of hormonal imbalance. A hybrid of fuzzy logic and GA techniques formed the soft computing model as shown in Figure 1.

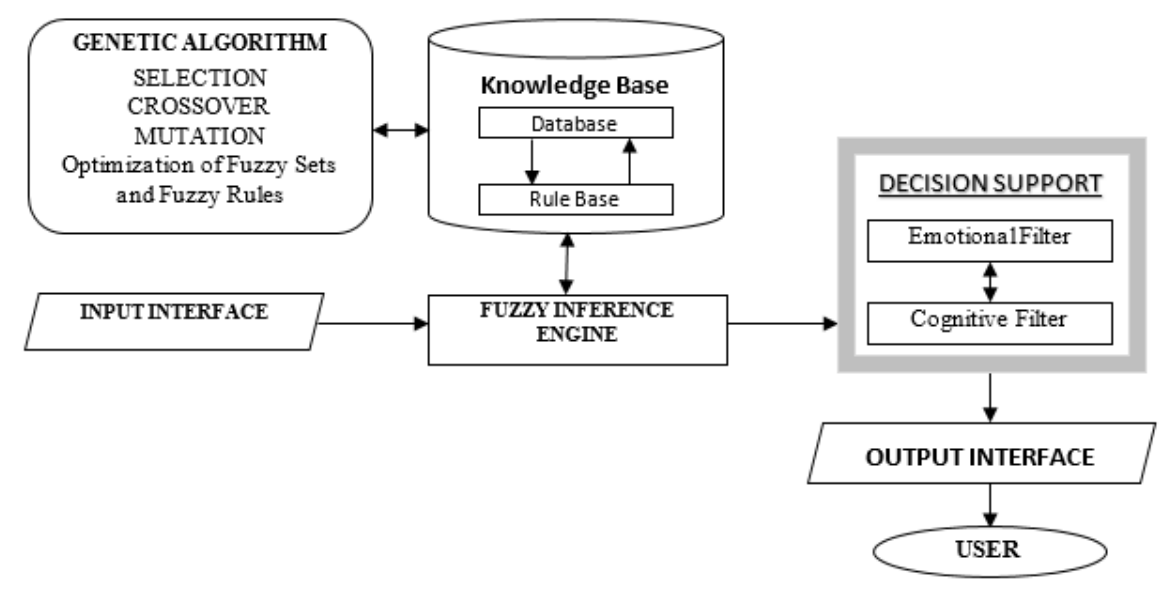

Figure 1: Model diagram for identifying the presence of Hormonal Imbalance

The various symptoms of Hormonal Imbalance, as elicited from domain experts, are stored in the Knowledge base. The input to this system could be in either structured or unstructured form which is converted to crisp fuzzy values/weights. These weights undergo genetic transformation to obtain a fitness function that enables the selection of the most significant symptoms for diagnosis.

Table 1 is a typical data set containing twenty symptoms that were obtained from medical experts. While zero (0) indicates the total absence of that symptom, one (1) shows that the symptom is at its peak. However, the degree of intensity of each symptom falls within the range of zero (0) and one (1). This means that the various elicited symptoms of Hormonal Imbalance and have their weight on a scale of 0 1. 
Ejodamen, Pius Uagbae, and Ekong, Victor Eshiet; Soft Computing System for the Diagnosis of Hormonal Imbalance. Transactions on Machine Learning and Artificial Intelligence, Volume 7 No 6 December (2019);

Table 1: Various forms of Hormonal Imbalance showing their degree of intensity

\begin{tabular}{|l|l|c|c|c|}
\hline \multirow{2}{*}{$\begin{array}{c}\text { Symptom } \\
\text { Codes }\end{array}$} & \multirow{2}{*}{$\begin{array}{l}\text { Symptoms/Fuzzy Set (Parameters) for } \\
\text { Identification of Hormonal Imbalance }\end{array}$} & \multicolumn{3}{|c|}{$\begin{array}{c}\text { Degree of Intensity of Hormonal } \\
\text { Imbalance }\end{array}$} \\
\cline { 3 - 5 } & & \multicolumn{2}{|c|}{ (Scale ranges from 0.00 - 1.00) } \\
\cline { 2 - 4 } & & Cluster 1 & Cluster 2 & Cluster 3 \\
\hline S01 & Headaches and Migraine & 0.40 & 0.30 & 0.30 \\
\hline S02 & Changes in menstruation & 0.12 & 0.15 & 0.73 \\
\hline S03 & Low sexual desire & 0.10 & 0.75 & 0.15 \\
\hline S04 & Weight gain & 0.74 & 0.16 & 0.10 \\
\hline S05 & Acne & 0.35 & 0.35 & 0.30 \\
\hline S06 & Oily skin & 0.73 & 0.15 & 0.12 \\
\hline S07 & Fever & 0.16 & 0.74 & 0.10 \\
\hline S08 & Fatigue & 0.14 & 0.74 & 0.12 \\
\hline S09 & Stress & 0.05 & 0.35 & 0.60 \\
\hline S10 & Frequent hunger & 0.45 & 0.30 & 0.25 \\
\hline S11 & Dizziness/Sleep Disorders & 0.35 & 0.35 & 0.30 \\
\hline S12 & Excessive hair growth & 0.12 & 0.73 & 0.15 \\
\hline S13 & Memory Fog & 0.30 & 0.30 & 0.40 \\
\hline S14 & Mood Swings and Depression & 0.05 & 0.19 & 0.76 \\
\hline S15 & Anxiety & 0.07 & 0.73 & 0.20 \\
\hline S16 & Allergy & 0.20 & 0.30 & 0.50 \\
\hline S17 & Endometriosis & 0.10 & 0.15 & 0.75 \\
\hline S18 & Infertility & 0.05 & 0.15 & 0.80 \\
\hline S19 & Urinary Tract Infections (UTIs) & 0.05 & 0.10 & 0.85 \\
\hline S20 & Premenstrual syndrome (PMS) & & 0.80 \\
\hline & & & \\
\hline
\end{tabular}

\subsection{Graphical Analysis of Disease Symptoms}

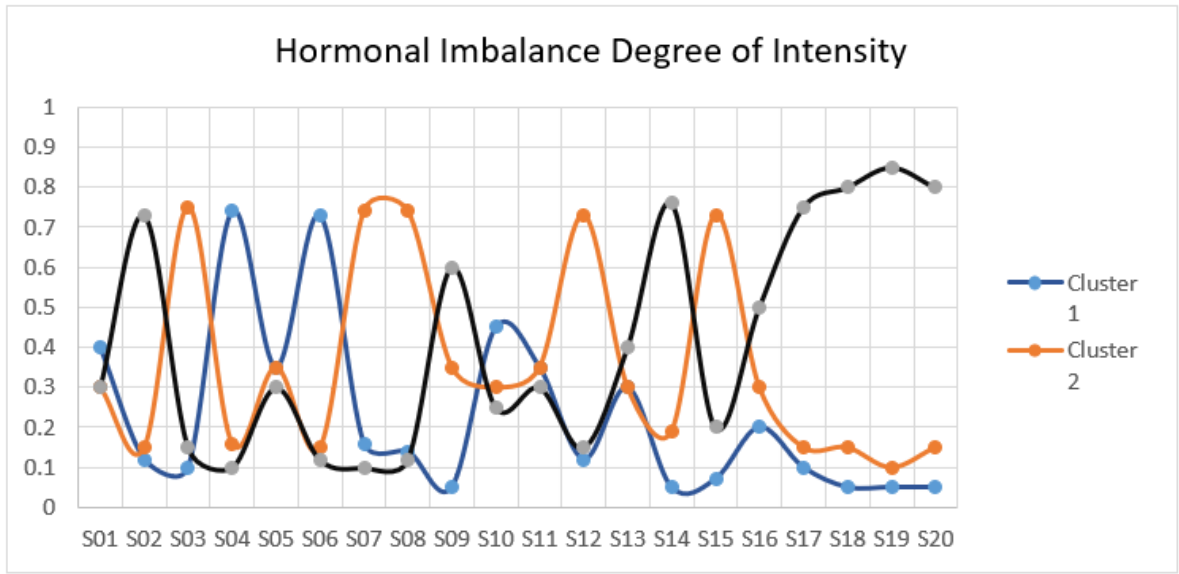

Figure 2: A graph showing symptoms of Hormonal Imbalance

Figure 2 shows a graph of the various symptoms of Hormonal Imbalance. From the graph, we see Cluster 1 has its highest peak at S04, while Cluster 2 has it at SO3, and its evident for Cluster 3 at S19. Notably, symptoms S17, S18, S19 and S20 shows a very higher chance that the individual has Hormonal Imbalance. However, at S05, S10, S12, and several other points, it becomes unclear whether or not to deduce that 
Hormonal Imbalance is present. This means that other ailments could have symptoms similar to those of hormonal imbalance.

\subsection{Analysis of the Genetic Algorithm component of system}

GA requires a random selection of values from the state space to form the initial generation. In this experiment, a random selection of individuals from the data set forms the first-generation parents. These weights are then encoded using Binary encoding - as this encoding method enables the representation of the weights as chromosomes and manipulation of its genes. While other crossover operators - such as Two-Point Crossover, Heuristic, Arithmetic, and Uniform - could have been applied, a One-point crossover operator was adopted for this study. The application of this operator encourages genetic diversity from one generation to another [16]. As shown in Table 2, two parents in the first generation were crossedover at bit $\mathbf{4}$ to produce a fresh offspring as the second generation. To further ensure genetic diversity, mutation operator was applied on some of the parent genes. Furthermore, same procedure was adopted on the second generation to produce the third generation offspring as shown in Table 3.

Table 2: First and Second Generation

\begin{tabular}{|c|c|c|c|c|c|}
\hline \multirow{2}{*}{ Code } & \multirow{2}{*}{ Selection } & \multicolumn{3}{|c|}{ Chromosomes } & $\begin{array}{c}\text { Fitness } \\
\text { Function }\end{array}$ \\
\cline { 3 - 6 } & & $\begin{array}{c}\text { Parent } \\
\text { (15t generation) }\end{array}$ & $\begin{array}{c}\text { Crossover/ } \\
\text { Mutation }\end{array}$ & $\begin{array}{c}\text { Offspring } \\
\text { (2nd generation) }\end{array}$ & \\
\hline S01 & 30 & 0011110 & $1 \& 18$ & 0011000 & 24 \\
\hline S02 & 70 & 1000110 & $2 \& 8$ & 1001001 & 73 \\
\hline S03 & 65 & 1000001 & $3 \& 4$ & 1001110 & 78 \\
\hline S04 & 30 & 0011110 & $3 \& 4$ & 0011001 & 25 \\
\hline S05 & 30 & 0011110 & $5 \& 14$ & 0011010 & 26 \\
\hline S06 & 25 & 0011001 & $6 \& 19$ & 0010101 & 21 \\
\hline S07 & 20 & 0010100 & $7 \& 20$ & 0011000 & 24 \\
\hline S08 & 25 & 0011001 & $2 \& 8$ & 0010110 & 22 \\
\hline S09 & 60 & 0111100 & $9 \& 13$ & 0111000 & 56 \\
\hline S10 & 25 & 0011001 & $10 \& 17$ & 0011011 & 27 \\
\hline S11 & 30 & 0011110 & $11 \& 16$ & 0011010 & 26 \\
\hline S12 & 25 & 0011001 & $12 \& 15$ & 0011101 & 29 \\
\hline S13 & 40 & 0101000 & $9 \& 13$ & 0101100 & 44 \\
\hline S14 & 50 & 0110010 & $5 \& 14$ & 0111110 & 62 \\
\hline S15 & 45 & 0101101 & $12 \& 15$ & 0101001 & 41 \\
\hline S16 & 50 & 0110010 & $11 \& 16$ & 0111110 & 62 \\
\hline S17 & 75 & 1001011 & $10 \& 17$ & 1001001 & 73 \\
\hline S18 & 80 & 1010000 & $1 \& 18$ & 1011110 & 94 \\
\hline S19 & 85 & 1010101 & $6 \& 19$ & 1011001 & 89 \\
\hline S20 & 80 & 1010000 & $7 \& 20$ & 1010100 & 84 \\
\hline & & & & & \\
\hline
\end{tabular}


Ejodamen, Pius Uagbae, and Ekong, Victor Eshiet; Soft Computing System for the Diagnosis of Hormonal Imbalance. Transactions on Machine Learning and Artificial Intelligence, Volume 7 No 6 December (2019);

Table 3: Next generation

\begin{tabular}{|c|c|c|c|c|c|}
\hline \multirow{2}{*}{ Code } & \multirow{2}{*}{ Selection } & \multicolumn{3}{|c|}{ Chromosomes } & \multirow{2}{*}{$\begin{array}{l}\text { Fitness } \\
\text { Function }\end{array}$} \\
\hline & & $\begin{array}{c}\text { Parent } \\
\left(2^{\text {nd }} \text { generation) }\right.\end{array}$ & $\begin{array}{l}\text { Crossover/ } \\
\text { Mutation }\end{array}$ & $\begin{array}{c}\text { Offspring } \\
\text { ( } 3^{\text {rd }} \text { generation) }\end{array}$ & \\
\hline S01 & 24 & 0011000 & $1 \& 3$ & 0011110 & 30 \\
\hline SO2 & 73 & 1001001 & $2 \& 4$ & 1001001 & 65 \\
\hline S03 & 78 & 1001110 & $1 \& 3$ & 1000000 & 64 \\
\hline SO4 & 25 & 0011001 & $2 \& 4$ & 0011001 & 17 \\
\hline S05 & 26 & 0011010 & $5 \& 17$ & 0011001 & 25 \\
\hline S06 & 21 & 0010101 & $6 \& 18$ & 0011110 & 30 \\
\hline S07 & 24 & 0011000 & $7 \& 20$ & 0010100 & 20 \\
\hline S08 & 22 & 0010110 & $8 \& 19$ & 0011001 & 25 \\
\hline S09 & 56 & 0111000 & $9 \& 12$ & 0111101 & 61 \\
\hline S10 & 27 & 0011011 & $10 \& 16$ & 0011110 & 30 \\
\hline S11 & 26 & 0011010 & $11 \& 14$ & 0011110 & 30 \\
\hline S12 & 29 & 0011101 & $9 \& 12$ & 0011000 & 24 \\
\hline S13 & 44 & 0101100 & $13 \& 15$ & 0101001 & 41 \\
\hline S14 & 62 & 0111110 & $11 \& 14$ & 0111010 & 58 \\
\hline S15 & 41 & 0101001 & $13 \& 15$ & 0101100 & 44 \\
\hline S16 & 62 & 0111110 & $10 \& 16$ & 0111011 & 59 \\
\hline S17 & 73 & 1001001 & $5 \& 17$ & 1000010 & 66 \\
\hline S18 & 94 & 1011110 & $6 \& 18$ & 1000101 & 69 \\
\hline S19 & 89 & 1011001 & $8 \& 19$ & 1000110 & 70 \\
\hline $\mathrm{S} 20$ & 84 & 1010100 & $7 \& 20$ & 1001000 & 72 \\
\hline \multicolumn{5}{|c|}{ Mean } & 45 \\
\hline \multicolumn{5}{|c|}{ Maximum } & 72 \\
\hline \multicolumn{5}{|c|}{ Minimum } & 17 \\
\hline
\end{tabular}

Table 3 shows the offspring generation which is decoded to form the fitness function. It can be observed that the offspring with the best fitness function is 72 which is said to be closest to the optimum solution. A weak offspring is more likely to go into extinction soon. Notably the weakest offspring is 17 and the mean for that generation is 45 . We use these values to define our fuzzy membership boundaries after conversion to fit the fuzzy format, which is $0.17,0.45$, and 0.72 for minimum, mean, and maximum points respectively.

\subsection{Fuzzy System}

This system applies Mamdani approach in designing the inference mechanism. In this study, the input and output attributes of the fuzzy system is determined. The identified 20 symptoms of hormonal imbalance are considered the input variables and one output (presence of Hormonal Imbalance) variable applies to this system design. Figure 3 shows the symptoms as input to the rule base which manipulates the data, based on certain rules to give the output. A centroid method is adopted for the defuzzification process and aggregate the inference of the fuzzy system. 


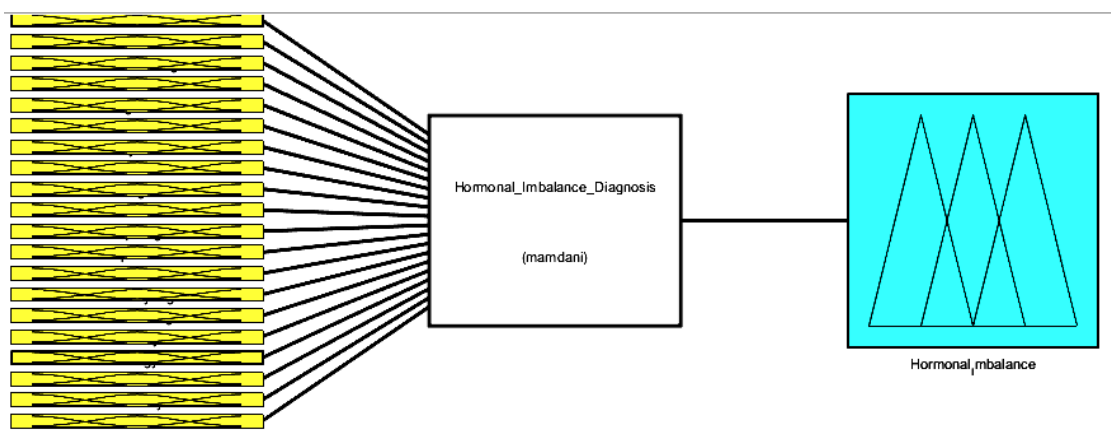

Figure 3: Symptoms of Hormonal Imbalance are mapped as input in the Fuzzy system

Membership function is the crux of fuzzy sets, associating each element of a domain to the set based of certain degree of membership. There are several types of membership function; the common ones include Triangular, Trapezoidal, and Gaussian functions. The domain expert determines the shape that suites the problem at hand. In this study, the triangular membership function has been adopted as used in several similar problem domains. This is illustrated in Figure 4 and define in Equation 1.

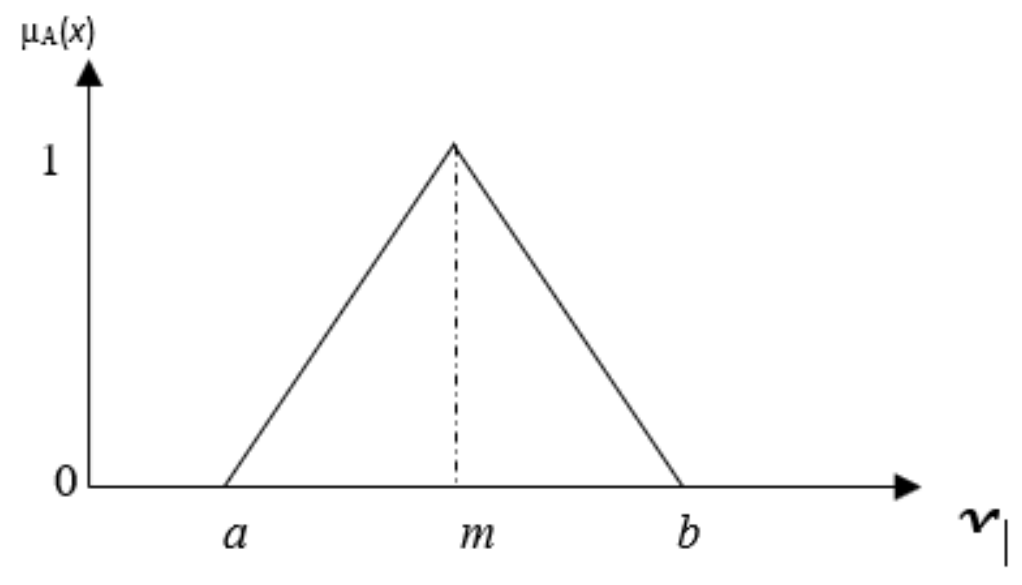

Figure 4: Triangular membership function

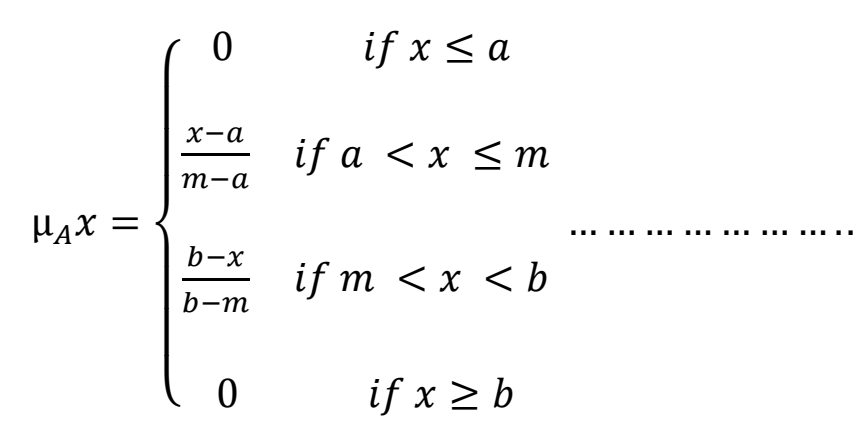

Membership function is required to classify the variables into linguistic labels: Mild, Moderate, Severe according to the degree of intensity of the patient's experience as shown in Equation 2. 


$$
\mu_{A} x= \begin{cases}\text { Mild } & \text { if } x \leq 0.45 \\ \text { Moderate } & \text { if } 0.45<x \leq 0.72 \ldots \ldots \ldots \ldots \ldots \ldots \ldots \\ \text { Severe } & \text { if } x \geq 0.72\end{cases}
$$

A Fuzzy membership function boundary of 0.72 was applied to determine the degree of intensity of the symptoms. The hormonal imbalance status of a patient can be classified, as illustrated in Figure 5, based on these basic rules:

i. Cluster 1 (C1): Hormonal Imbalance is Not Present

ii. $\quad$ Cluster 2 (C2): Hormonal Imbalance May Be Present

iii. $\quad$ Cluster 3 (C3): Hormonal Imbalance is Present

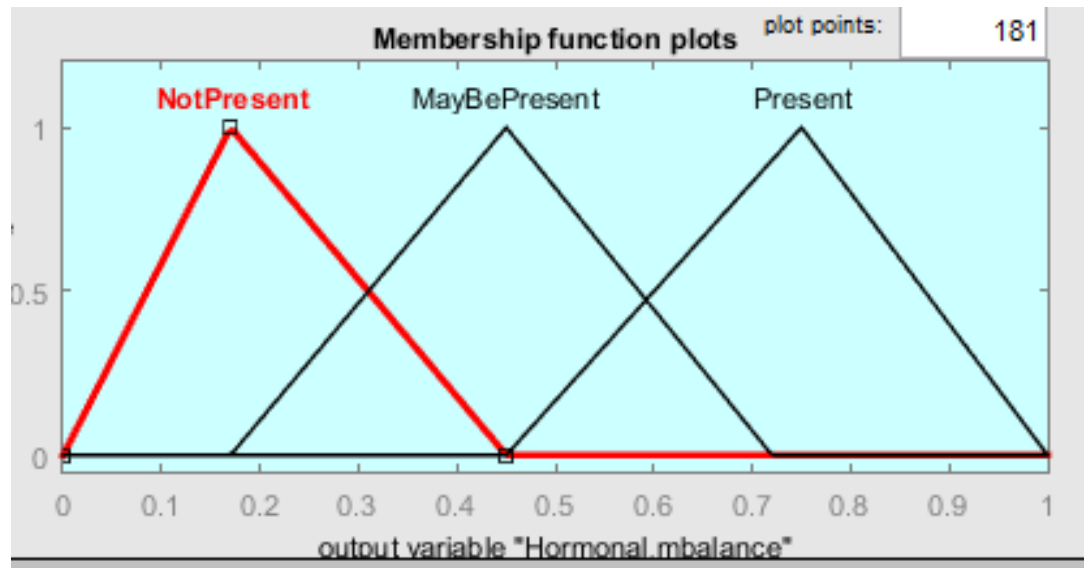

Figure 5: Triangular membership function for diagnosing the presence of Hormonal Imbalance

The quality of the results obtainable from a fuzzy system is dependent on the rule base of the system [21]. The following are some of the generated Fuzzy IF-THEN rules applied for the diagnosis of hormonal imbalance. Rule R1, for instance, implies that the patient experiences severe headache/migraine while other symptoms are mild. Similarly, rule R5 indicates that a patient may be having hormonal imbalance if $s /$ he is experiencing severe Headaches and Migraine, Changes in menstruation, Low sexual desire, Weight gain and Acne. Fuzzy toolkit rule editor in MATLAB, as shown in Figure 6, aided our generation of the Fuzzy rules. 


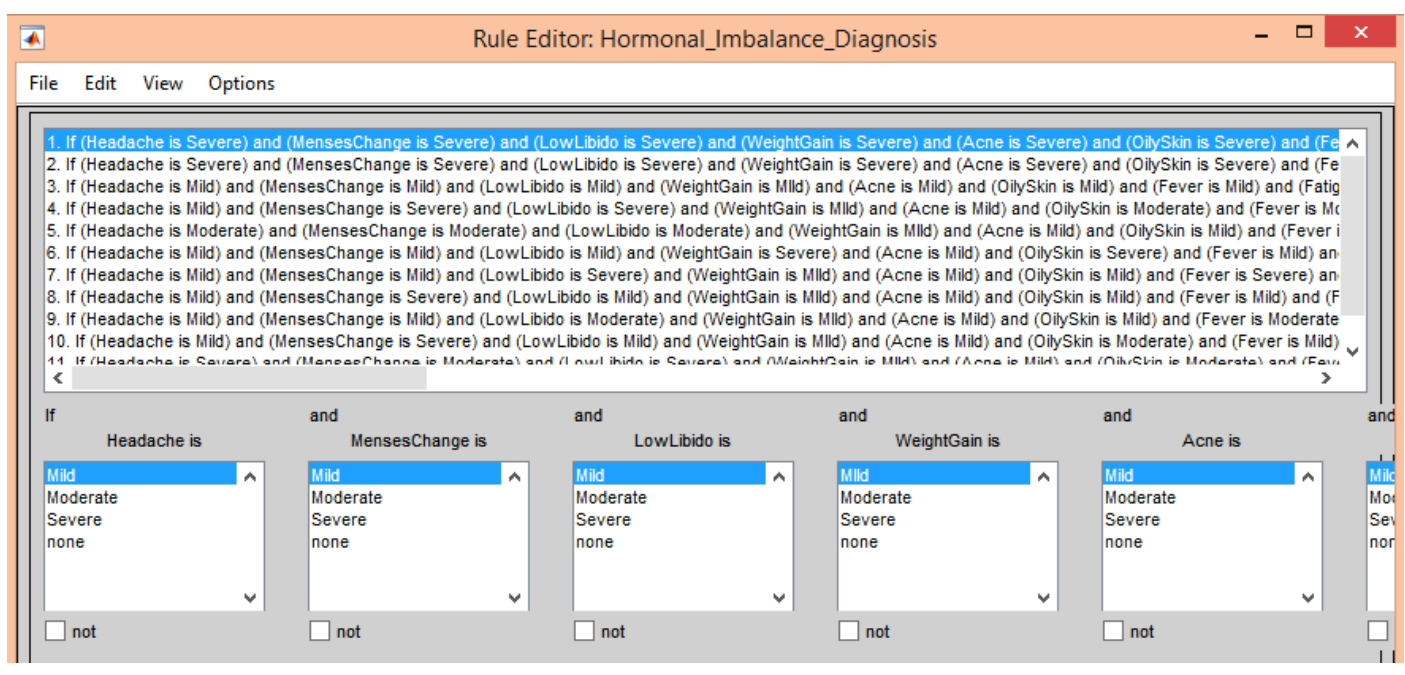

Figure 6: Rules generated for Fuzzy Inferencing

R1: IF patient experiences Headaches and Migraine THEN diagnose C1

R2: IF patient experiences Headaches and Migraine and Changes in menstruation THEN diagnose C1

R5: IF patient experiences Headaches and Migraine and Changes in menstruation and Low sexual desire and Weight gain and Acne THEN diagnose C2

R6: IF patient experiences Headaches and Migraine and Changes in menstruation and Low sexual desire and Weight gain and Acne and Oily skin THEN diagnose C3

R14: IF patient experiences Headaches and Migraine and Changes in menstruation and Low sexual desire and Weight gain and Acne and Oily skin and Fever and Fatigue and Stress and Frequent hunger and Dizziness/Sleep Disorders and Excessive hair growth and Memory Fog and Mood Swings/Depression THEN diagnose C3

R15: IF patient experiences Headaches and Migraine and Changes in menstruation and Low sexual desire and Weight gain and Acne and Oily skin and Fever and Fatigue and Stress and Frequent hunger and Dizziness/Sleep Disorders and Excessive hair growth and Memory Fog and Mood Swings/Depression and Anxiety THEN diagnose $\mathrm{C} 3$

R20: IF patient experiences Headaches and Migraine and Changes in menstruation and Low sexual desire and Weight gain and Acne and Oily skin and Fever and Fatigue and Stress and Frequent hunger and Dizziness/Sleep Disorders and Excessive hair growth and Memory Fog and Mood Swings/Depression and Anxiety and Allergy and Endometriosis and Infertility and Urinary Tract Infections and Premenstrual syndrome THEN diagnose C3.

\section{Result and Discussion}

The generated data from Table 1 was simulated using Matrix Laboratory (MATLAB) R2015a to obtain our result. Figure 7 shows a sample simulation of the diagnosis of hormonal imbalance based on selected patient's symptoms. The choice of MATLAB is due to its robust applicability, availability of useful tools such as the Fuzzy Logic Toolbox, data visualization, and an interactive environment for developing algorithms. 
Ejodamen, Pius Uagbae, and Ekong, Victor Eshiet; Soft Computing System for the Diagnosis of Hormonal Imbalance. Transactions on Machine Learning and Artificial Intelligence, Volume 7 No 6 December (2019); pp: $30-42$

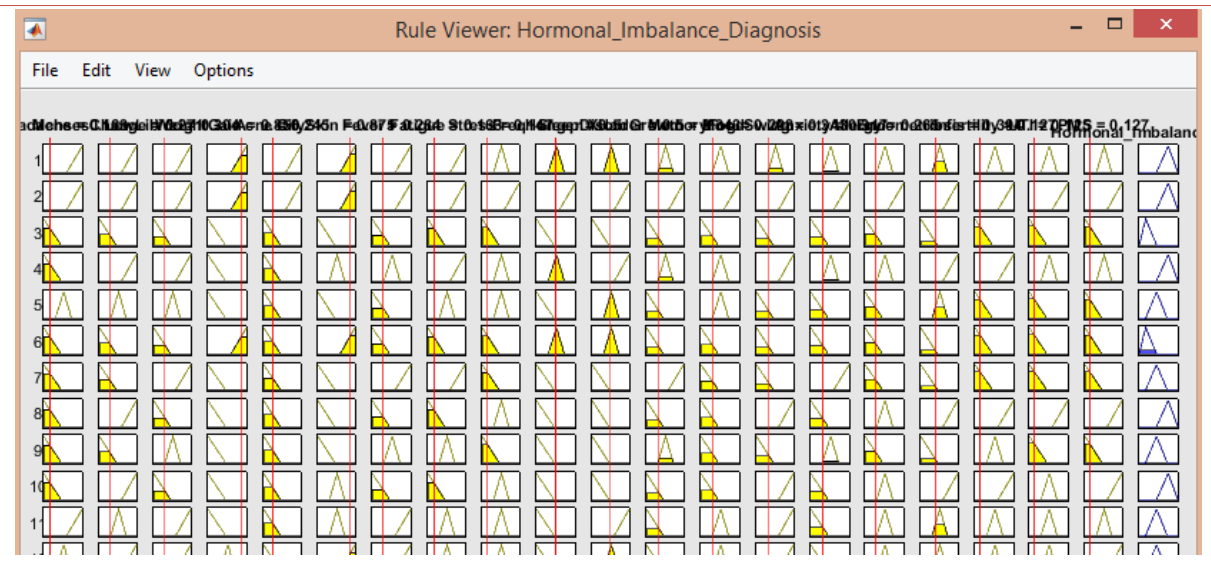

Figure 7: Simulation of hormonal imbalance diagnosis.

Table 4: Data set showing the degree of membership for Hormonal Imbalance

\begin{tabular}{|c|c|c|c|c|}
\hline \multirow[t]{2}{*}{$\begin{array}{c}\text { Symptom } \\
\text { Codes }\end{array}$} & \multirow[t]{2}{*}{$\begin{array}{l}\text { Symptoms/Fuzzy Set } \\
\text { (Parameters) for Identification } \\
\text { of Hormonal Imbalance }\end{array}$} & \multicolumn{3}{|c|}{$\begin{array}{l}\text { Degree of Membership Function for } \\
\text { Hormonal Imbalance (Scale ranges from } \\
0.00-1.00 \text { ) }\end{array}$} \\
\hline & & Cluster 1 & Cluster 2 & Cluster 3 \\
\hline S01 & Headaches and Migraine & 0.40 & 0.30 & 0.30 \\
\hline S02 & Changes in menstruation & 0.12 & 0.15 & 0.73 \\
\hline S03 & Low sexual desire & 0.10 & 0.75 & 0.15 \\
\hline SO4 & Weight gain & 0.74 & 0.16 & 0.10 \\
\hline S05 & Acne & 0.35 & 0.35 & 0.30 \\
\hline S06 & Oily skin & 0.73 & 0.15 & 0.12 \\
\hline S07 & Fever & 0.16 & 0.74 & 0.10 \\
\hline S08 & Fatigue & 0.14 & 0.74 & 0.12 \\
\hline S09 & Stress & 0.05 & 0.35 & 0.60 \\
\hline S10 & Frequent hunger & 0.45 & 0.30 & 0.25 \\
\hline S11 & Dizziness/Sleep Disorders & 0.35 & 0.35 & 0.30 \\
\hline S12 & Excessive hair growth & 0.12 & 0.73 & 0.15 \\
\hline S13 & Memory Fog & 0.30 & 0.30 & 0.40 \\
\hline S14 & Mood Swings and Depression & 0.05 & 0.19 & 0.76 \\
\hline S15 & Anxiety & 0.07 & 0.73 & 0.20 \\
\hline S16 & Allergy & 0.20 & 0.30 & 0.50 \\
\hline S17 & Endometriosis & 0.10 & 0.15 & 0.75 \\
\hline S18 & Infertility & 0.05 & 0.15 & 0.80 \\
\hline S19 & Urinary Tract Infections (UTIs) & 0.05 & 0.10 & 0.85 \\
\hline S20 & Premenstrual syndrome (PMS) & 0.05 & 0.15 & 0.80 \\
\hline & DIAGNOSIS RESULT & $\begin{array}{c}\text { Hormonal } \\
\text { Imbalanc } \\
\text { e is Not } \\
\text { Present }\end{array}$ & $\begin{array}{c}\text { Hormonal } \\
\text { Imbalance } \\
\text { Maybe } \\
\text { Present }\end{array}$ & $\begin{array}{l}\text { Hormonal } \\
\text { Imbalance is } \\
\text { Present }\end{array}$ \\
\hline
\end{tabular}

Table 4 represents the degree of intensity of hormonal imbalance. For example, Symptom S02 (Changes in menstruation) with a weight of 0.73 implies $73 \%$ likelihood that the symptom could result in Hormonal Imbalance is being diagnosed. Also, symptom S15(Anxiety) with a weight of 0.07 indicates $7 \%$ of Hormonal Imbalance not present, $73 \%$ that it may be present, and $20 \%$ chance that it is certainly present. However, with symptom S05 (Acne), the uncertainty is higher with a weight of 0.35 which implies that Hormonal Imbalance may or may not exist for that individual. 
They are some symptoms, such as headache and fever that could be a pointer to several other ailments such as Malaria, Typhoid, Tuberculosis, as evident in other studies [20-22]. The technique in this study handles fuzziness and uncertainty to produce diagnosis that agrees with other researchers [1-3].

\section{Conclusion}

This study demonstrates the practical hybridization of Fuzzy Logic and GA as a soft computing technique in diagnosing medical problems such as hormonal imbalance. This system is an interactive system that optimizes imprecise and incomplete data to produce reliable diagnosis of hormonal imbalance. The system developed in this study can serve as a useful support tool for medical practitioners in diagnosing cases of hormonal imbalance. Future research may consider applying this technique is diagnosing neglected tropical diseases and health conditions.

\section{REFERENCES}

[1] Haybach, P. J. (2006). Hormones and Vestibular Disorders. Vestibular Disorders Association, Portland.

[2] Helal, I. A., Mohammed, Z. S., Muhson, H. D., Ali, E. S., \& Majeed, M. R. (2015). Association between female infertility and hormonal imbalance. College of Nursing, University of Kufa. DOI: 10.13140/RG.2.1.1222.5041.

[3] Bunzenmeyer, J. (2016). What does hormone imbalance mean and how can it affect me? Retrieved online from www.ndclinic.com.

[4] Kyle, C. A. (2008). A handbook for the interpretation of laboratory tests $.4^{\text {th }}$. ed., diagnostic Medlab, pp: 345.

[5] Cooper T. G., Noonan E., von Eckardstein S., Auger J., Baker H.W.G., Behre H. M., Vogelsong K. M. (2010). World Health Organization reference values for human semen characteristics, Human Reproduction Update, Vol. 16, No. 3, pp. 231-245.

[6] Wolfe D. (2016). 10 Signs and Symptoms of Hormonal Imbalance. Retrieved online from www.docofdetox.com

[7] Naveed, S., Ghayas, S., Hameed, A. (2015). Hormonal imbalance and its causes in young females. Journal of Innovations in Pharmaceuticals and Biological Sciences (JIPBS), Vol. 2, No. 1, pp.12-16.

[8] Bigus C (2013). Nine Signs You Have a Hormonal Imbalance + Easy Ways to Fix it. Retrieved from www.mindbodygreen.com.

[9] Hills J. (2014). 13 Signs You Have a Hormonal Imbalance and What You Can Do About it. Healthy and Natural World. Retrieved from www.healthyandnaturalworld.com

[10] Adaikan, P. G. and B. Srilatha (2003) Oestrogen-mediated hormonal imbalance precipitates erectile dysfunction, International Journal of Impotence Research 15:38-43.

[11] MedicineNet (2019) Hormone imbalance, https://www.medicinenet.com/search/mni/hormonal\%20imbalance Assessed 20-11-2019

[12] Tarantino G, Savastano S, Colao A. (2010) Hepatic steatosis, low-grade chronic inflammation and hormone/growth factor/adipokine imbalance. World J Gastroenterol; Vol. 16, No. 38, pp.4773-4783, Available at: http://www.wjgnet.com/1007-9327/full/v16/i38/4773.htm DOI: http://dx.doi.org/10.3748/wjg.v16.i38.4773. 
Ejodamen, Pius Uagbae, and Ekong, Victor Eshiet; Soft Computing System for the Diagnosis of Hormonal

Imbalance. Transactions on Machine Learning and Artificial Intelligence, Volume 7 No 6 December (2019); pp: 30-42

[13] Singh, A., \& Kaur, R. A (2015). Study of Hybrid Soft Computing Techniques. International Journal of Advance Foundation and Research in Science \& Engineering (IJAFRSE).

[14] Parthiban, L., \& Subramanian R. (2007). Intelligent Heart Disease Prediction System using CANFIS and Genetic Algorithm. World Academy of Science, Engineering and Technology International Journal of Medical and Health Sciences Vol. 1, No. 5.

[15] Zadeh, L.A (1965) Fuzzy sets. Inform Control, Vol. 8, No. 3, pp.338-353.

[16] Ejodamen, P. U., \& Imianvan, A. A. (2018). Genetic Neuro-Fuzzy System for the Identification of Citrus Huanglongbing. 27 th National Conference, Nigeria Computer Society (NCS), University of Ibadan, Oyo State, Nigeria.

[17] Ekong, V. E., Inyang, U. G., \& Onibere, E. A. (2012). Intelligent Decision Support System for Depression Diagnosis Based on Neuro-fuzzy-CBR Hybrid. Modern Applied Science; Vol. 6, No. 7, pp. 79-88.

[18] Vijaya, K., Nehemiah, H. K., Kannan, A., and Bhuvaneswari, N.G. (2010). Fuzzy Neuro Genetic Approach for Predicting the Risk of Cardiovascular Diseases. International Journal of Data Mining, Modeling and Management, Vol. 2, No. 4, pp. 388-402. Available at: http://dx.doi.org/10.1504/IJDMMM.2010.035565

[19] Uzoka F-M. E., Obot O., Barker K., \& Osuji J. (2011). An experimental comparison of fuzzy logic and analytic hierarchy process for medical decision support systems. Computer Methods and Programs in Biomedicine 103 (2011) 10-27.

[20] Obot, O. U. and Uzoka, F-M. E. (2008). Fuzzy rule-based framework for the management of tropical diseases. Int. J. Medical Engineering and Informatics, Vol. 1, No. 1.

[21] Imianvan, A. A., \& Obi, J. C. (2012). Decision Support System for the Identification of Tuberculosis using Neuro Fuzzy Logic. Nigerian Annals of Natural Sciences, Vol. 12, No. 1, pp.12- 20.

[22] Obi, J. C., Imianvan, A. A. \& Ekong, V. E. (2012). Genetic Neuro-Fuzzy System for the Intelligent Recognition of Stroke, Journal of Computer Science and its applications, An International Journal of The Nigeria Computer Society, Vol. 19, No.1, pp. 24-31. 